\title{
corrigendum
}

\section{Evolutionarily conserved networks of residues mediate allosteric communication in proteins}

Gürol M. Süel, Steve W. Lockless, Mark A. Wall and Rama Ranganathan

Nat. Struct. Biol. 10, 59-69 (2003).

Because of resolution mismatch, Figs. $3 c, 5 c, d, 7 b, c$ of this paper appear blurry in print. The pixels in these matrices have sharp edges, and the correct panels are now reprinted. We apologize for any inconvenience this may have caused.

Fig. 3c

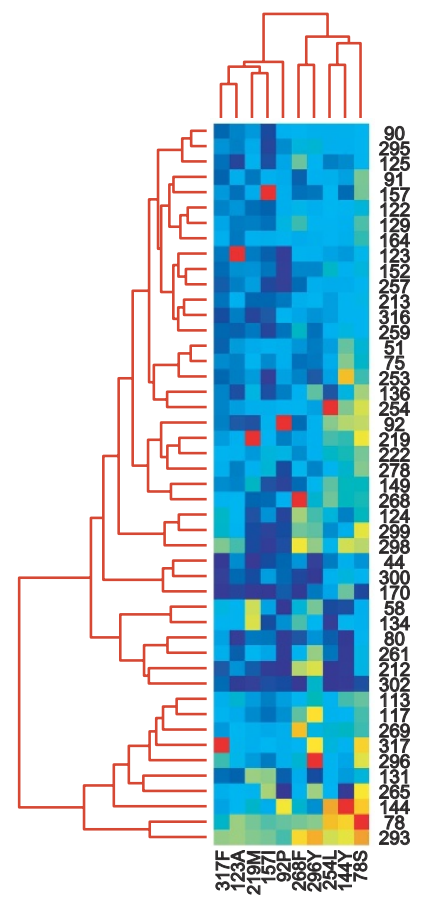

Fig. $7 b$
Fig. $5 c$

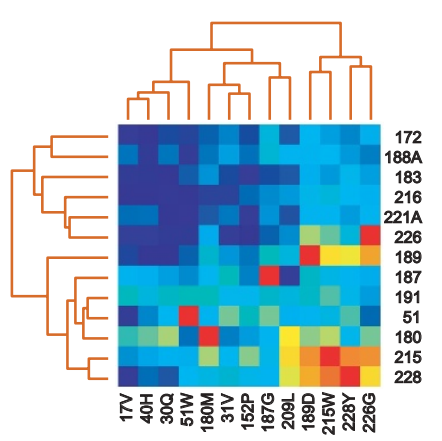

Fig. $5 d$

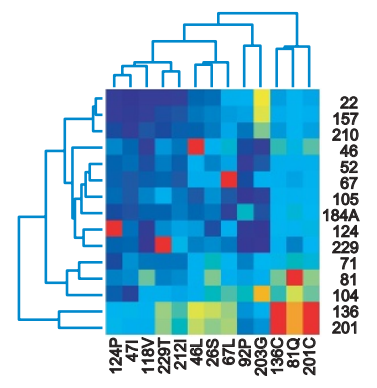

Fig. $7 c$

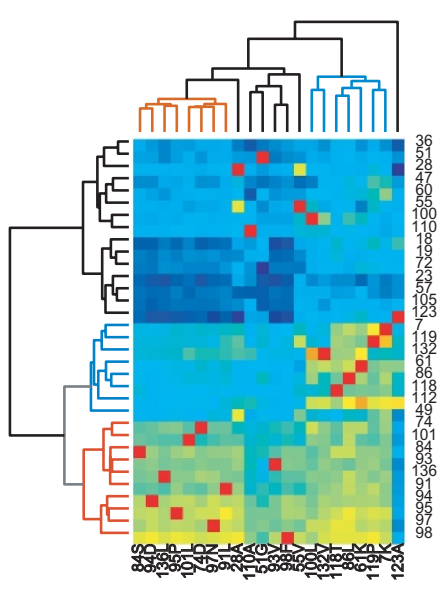

